

\section{Place as a Nexus for Corporate Heritage Identity: An International Study of Family-Owned Wineries}

First submission: February 2017

First revision: August 2017

Second revision: February 2018

Third revision: May 2018

Fourth revision: December 2018

Fifth revision: March 2019

Nathalie Spielmann, Associate Professor, Marketing, NEOMA Business School, 59 rue Pierre Taittinger, 51100 Reims, France, nathalie.spielmann@neoma-bs.fr, 33-3-26-77-56-71.

Allan Discua Cruz, Lecturer, Entrepreneurship, Strategy \& Innovation, Lancaster University Management School, UK, a.discuacruz@lancaster.ac.uk, 44-1524-510722.

Beverly B. Tyler, Professor, Management, Innovation and Entrepreneurship, North Carolina State University, Poole College of Management, 2801 Founders Drive, Raleigh, NC 27695, btyler@ncsu.edu, 919-621-1145.

Karin Beukel, Assistant Professor, Innovation and Entrepreneurship, University of Copenhagen, Rolighedsvej 25, DK-1958 Frederiksberg, kab@ifro.ku.dk, 45-35-32-08-95.

The authors would like to thank the following people for their help with data collection: Greg

Young (North Carolina State University) and Marco Minciullo and Donatella Depperu (Università Cattolica - Piacenza). The authors acknowledge their help and involvement, which certainly made this project richer. The authors would also like to thank Katy Mason (Lancaster University) and Brooke Lahneman (Simon Fraser University) for their help during the revision process. 


\title{
Place as a Nexus for Corporate Heritage Identity: An International Study of Family-Owned Wineries
}

\begin{abstract}
This paper uncovers the dynamic and reciprocal relationship between corporate heritage identities and corporate heritage brands. Through an examination of the role of place in the marketing strategies of seven family-owned wineries, in six countries, we explain how these wineries use their place to create and incorporate consistency with change in their marketing strategies. The cross-cultural case analysis of multigenerational and long-established, as well as novel and fledgling wineries, showcases how multiple role identities of wineries interact with the relative invariance of place to infuse corporate heritage identities and corporate heritage brands, and vice-versa. The results build on corporate heritage literature by providing an in-depth illustration of the role of place and corporate heritage identity interactions in the development of a firm's marketing strategy. The results are especially relevant for firms offering products anchored in a geographic origin.
\end{abstract}

Keywords: Corporate Heritage Identity; Corporate Heritage Brands; Relative Invariance; Multiple Role Identities; Place; Wine. 


\section{Place as a Nexus for Corporate Heritage Identity: An International Study of Family-Owned Wineries}

\section{Introduction}

Around the world, wines embody and connect aspects of a place - its history, geography, the soil, the grape variety, the climate, the weather, cultural identity, a region and its expertise and heritage in winemaking - in their production and marketing. How then can wineries make use of place, and more specifically place heritage, in the development of a corporate brand when they already have a corporate heritage identity and a corporate heritage brand? To address this question, this study draws on corporate heritage identity and corporate heritage brand theory (Balmer, 2011b) to reveal how managers develop winery-marketing strategies. Corporate heritage identities encompass institutional attributes and qualities that meaningfully define an organization's identity, whereas corporate heritage brands encompass the institutional promises and stakeholder expectations that are associated with the corporate brand name and marque (Balmer, 2011b). Corporate heritage brands make promises rooted in the past, present and future, allowing them to remain relatively invariant - encompassing continuity and change - thus helping to create corporate heritage identities with institutional traits that remain meaningful and invariant through time (Balmer \& Chen, 2017; Balmer, 2011a, Balmer, 2011b; Urde, Greyser, \& Balmer, 2007; Balmer, Greyser, \& Urde, 2006; Balmer \& Burghausen, 2019). But corporate heritage brands often relate to multiple companies, suggesting that corporate heritage identities can depend on multiple entities, often extending outside of the boundaries of the firm (Balmer, 2013). This suggests that the development of corporate heritage brands is likely to be influenced by the multiple, complex roles of corporate heritage identities. 
Corporate heritage identities are often composites of the various identities that firms develop through their different roles: for example, their symbiotic relationship with other heritage brands associated with place, communities, and professions - many chateaux in Bordeaux are associated with the Place de Bordeaux, which is a heritage identity of place, a custodian of wine quality, and a market-maker for quality wines (Spielmann, 2014; Thach \& Charters, 2016). The claim is that corporate heritage identities become meaningful precisely because they encompass multiple role identities at the same time (Balmer, 2011a; 2013). Such roles might be covert and tacit, overt and communicated (Balmer \& Greyser, 2002; Balmer, 2013), and are encompassed at the macro level (e.g., for corporate purposes, to demonstrate competencies, cultures, philosophies) and micro level (e.g., incorporated into design, advertising and communication, architectural heritage), enabling firms to mobilize different aspects of corporate heritage identity in order to accomplish multiple objectives (Balmer, 2011a). This observation seems particularly pertinent for the marketing of wineries, but the extant literature still says little about the role of place in the formation and interaction of corporate heritage identities and corporate heritage brands.

Where the corporate heritage identities literature has paid attention to place, its treatment has tended to be as a cultural context (see for example, Balmer, Greyser, \& Urde's (2006) treatment of the British Monarchy, and Balmer \& Chen's (2015) examination of the Chinese corporate brand Ton Ren Tang). In each case, it is the institutional norms, discourses, symbols and values that are anchored in time and place, with their meaningful use creating corporate brand continuance (Balmer, 2011a; Balmer \& Burghausen, 2019). Even when produced through imagination, ingenious thinking or experiments, corporate heritage identities can be used to communicate a notion of time and place in ways that become meaningful to consumers 
(Brunninge \& Hartmann, 2019). Yet the example of Bordeaux invokes a new multiplicity: while Bordeaux has many châteaux, each with their own corporate heritage identity, it is both a single place (a geographic region of France) and a number of places (with châteaux spread across the Bordeaux region). Yet, to the best of our knowledge there are no extant studies that have contrasted multiple corporate heritage identities and corporate heritage brands across a variety of places from a marketing strategy perspective.

This study is a response to recent calls for corporate heritage identity and corporate heritage brand studies that cross multiple countries and cultures (Balmer \& Burghausen, 2015; Balmer \& Chen, 2015). We argue that in addition to the role of corporate heritage identities in shaping corporate heritage brands, the complexities and relative invariance of place can play a critical role in their interaction. We move beyond extant research that reveals how corporate brands create, structure and enable the corporate heritage identities in places (Balmer, 2011a) by explicating the heritage identities of a particular place, as these identities inform the corporate heritage identities of a corporate brand (cf. Charters and Spielmann, 2016). The study argues that place and corporate heritage identities entangle in a nexus of practice that is particularly salient in settings where place heritage forms part of corporate heritage identity and corporate heritage brands.

Just as the notion of corporate heritage is omni-temporal (Balmer \& Burghausen, 2019; Balmer, 2013), so is wine as a beverage: it is evocative of the past (7000+ years of history), is produced in the present, and can be aged for the future. In addition to being inspired by the Latin idiom, in vino veritas, (in wine there is truth), we position our study in the wine industry because of three, omni-temporal characteristics (cf. Balmer \& Burghausen, 2019): 1) wine is intrinsically linked to the place where the vines are planted (Patterson, Buechsenstein, \& Freeman, 2018); 2) most wineries co-operate regionally, working with other firms to build regional identities 
(Charters \& Spielmann, 2014; Spielmann \& Williams, 2016); and 3) most wineries are familyrun and controlled. Diverse cultural practices across wineries often align with family-firm origins. Thus, wineries are dependent on the identity of their heritage (Thach \& Charters, 2016). These truths inform the corporate heritage identities and corporate heritage brands established by wineries: encompassing the firm, the region, the family and the other firms within the region. Further, winemaking takes place in two distinct places: the Old World (where wine has been produced for centuries: France, Italy) and the New World (where winemaking is relatively new: Canada, UK, USA and Denmark) (Banks \& Overton, 2010), providing an ideal setting to study how place informs the corporate heritage identities of family-owned wineries. Adopting this sampling logic, this study compares seven wineries from the Old and New Worlds to see how different wineries use place to develop corporate heritage identity and corporate heritage brands. Using an interpretive approach (Hamilton, Discua Cruz, \& Jack, 2017) we analyze the seven cases using corporate heritage identity and corporate heritage brand traits (Balmer, 2011a; Charters \& Spielmann, 2016) to generate a comparative cross-cultural analysis.

Our research builds on Balmer's (2011a, 2011b, 2013) groundbreaking work on corporate heritage identity and corporate heritage brands by revealing the situated nature of their symbiotic relationship to produce a place heritage identity and territorial heritage brand in the development of winery marketing strategies. This extends extant understanding by explicating the mutability through time of heritage in corporate identity and corporate heritage branding (cf. Balmer 2011a), by showing that agency does not lie solely within a firm but rather is distributed across a community, anchored in place by multiple actors. 


\section{Theoretical Background}

\subsection{Corporate Heritage Identity and Corporate Heritage Branding}

When a firm chooses to use heritage as a marketing cue, it creates a corporate heritage identity. Heritage is not history: heritage is an active use and consideration of history (the past and present), whereas history focuses on the past. Heritage is considered as a legacy and a collective identity that persists and is perpetuated over time (Macdonald, 2006). As such, heritage can be an anchor that communicates certainty in an evolving world; a totem of consistency and clarity (Lowenthal, 1998). Furthermore, heritage can be a material testimony and a set of practices that can be objectified (Macdonald, 2006). Yet Balmer (2011a) posits that for firms using these practices, "heritage identities are an accretion of various identities, which are variously linked to institutions, places, cultures, and to time frames" (Balmer, 2011a, p. 1380). Moreover, Balmer (2011a) puts forward that while heritage is closely linked to history, in corporate marketing and in corporate branding contexts, it relates to the present as well as to the past and to the future. In doing so, corporate heritage differs from the conventional association of heritage with institutions and focuses on enduring heritage institutions and corporate brands (Balmer, 2011a). Corporate heritage thus refers to "...all the traits and aspects of an organisation that link its past, present, and future in a meaningful and relevant way." (Burghausen \& Balmer, 2014b, pp. 394-395).

By using its heritage identity in marketing and management contexts, a firm affirms its unique corporate heritage identity and provides an omni-temporal dimension to the firm's positioning (Blömback and Brunninge, 2013). Accordingly, corporate heritage identity includes any of the following traits at the macro and micro level: culture, philosophy, corporate competencies, activities, markets, groups, visual identity, and other expressive features that have implications for the firm's actions and strategies, as well as design characteristics and corporate 
branding choices (Balmer, 2011a). Consequently, corporate heritage identity refers to "those institutional traits which have remained meaningful and invariant over the passage of time and, as such, a corporate heritage identity is viewed as being part of the past, present and future" (Balmer, 2011a, p. 1385). Specifically, corporate heritage identities are shaped by the past but they also shape the past by using the past in order for it to have meaning in the present, future and over time (Balmer \& Burghausen, 2015; Moingeon \& Ramanantsoa, 1997); they become relatively invariant (Balmer, 2011a).

Place and culture are an essential part of the corporate heritage identity canon (Urde et al., 2007), contributing to the "one of a kind" nature of corporate heritage identity (Balmer, 2017). Prior research has often examined single cases of corporate heritage identity within a culture, thereby accentuating the relevance of corporate heritage brands (Balmer \& Burghausen, 2015). While the bulk of research has focused on corporate heritage brands in specific countries, such as the United Kingdom (Balmer, 2009, 2011a, b) or China (Balmer \& Chen, 2015; Schroeder, Borgerson \& Wu, 2015), the comparison between countries remains limited (with the exception of Blömback \& Brunninge, 2013). For example, there have been many significant advances based on the British Monarchy (Balmer, 2011a; Balmer, 2011b; Balmer, 2013; Balmer, Greyser, \& Urde, 2006; Balmer, 2009; Urde, Greyser, \& Balmer, 2007). There is also recent work on the Chinese corporate brand Ton Ren Tang (Balmer \& Chen, 2015; Balmer \& Chen, 2016; Balmer \& Chen, 2017) as well as the Chinese corporate brands Shanghai Tang and Shang Xia (Schroeder, Borgerson, \& Wu, 2015). Finally, extensive work has also been conducted on Shepherd Neame, Great Britain's oldest brewers (Burghausen \& Balmer, 2014a, 2015). A focus on specific contexts has revealed that what all of these cases have in common is their unique and certainly very powerful and ancient presence within the culture. For example, Shepherd Neame has been brewing since 1698 and Ton Ren Tang was founded in 1669. In such organizations, particular 
identity traits "have endured and meaningfully link its past, present and prospective future" (Burghausen \& Balmer, 2014a, p. 2311). As such, these entities have "identities that subsist in temporal strata" (Balmer, 2011a, p. 1386).

Furthermore, many corporate heritage identities are constructed based on family histories, or the heritage of unique founders who have come to represent an origin. The British Monarchy's corporate heritage identity relies on the United Kingdom's Kings and Queens (Balmer, 2009), Tim Horton's coffee shops in Canada rely on the eponymous hockey legend (Cormack, 2008; Foster, Suddaby, Minkus, \& Wiebe 2011), and the Cunard cruise ship company name honors its British-Canadian founders Edward and Samuel Cunard (Hudson, 2011). Family members in the business impact the choices that firms make over time and they are strongly linked to the past, present and long-term outlook of a business (e.g., Chrisman, Sharma, \& Taggar, 2007; Melin, Nordqvist, \& Sharma, 2014). The influence and uniqueness of family in a firm's strategic positioning are appreciated in long-standing as well as new family firms, because both become dependent on family heritage to introduce and market their products (Roscoe, Discua Cruz, \& Howorth, 2013). And while for family businesses the obvious financial, human, psychological, and social capital resources are critical for performance and distinctiveness, so are governance structures and cultural influences (Chrisman et al., 2007; Kim \& Gao, 2013). It is often the historical interaction between the family, the firm, and its cultural environment that determines firm survival over generations (Blömback \& Brunninge, 2013; Melin et al., 2014). Thus, the place or origin heritage appears to create a unique and lasting competitive advantage for firms, especially family firms, by contributing to corporate heritage identity (Burghausen \& Balmer, 2014a). More specifically, the consciousness of place and the sense a firm has of belonging to a place can shape corporate heritage identity (Burghausen \& Balmer, 2017); place then can integrate itself as part of the multiple role identities of a corporate heritage 
identity, but also contribute to its relative invariance.

\subsection{Corporate Heritage Identity, Corporate Heritage Branding, and Place}

The importance of spatial context, or territorial origin, in terms of identity creation has recently received renewed attention in marketing and management literature, although it has often been subsumed in the literature on corporate heritage identities (Balmer, 2011a). From the supranational scale to the local scale, "the link between heritage and locality, and between locality and identity, must then be argued" (Ashworth, 2013, p. 14). Clearly, for businesses that produce a place-based product, it would be myopic to examine their corporate heritage identities without considering the environment in which such businesses are run. For example, when firms identify the origin of their product, they must often adopt, in addition to their own corporate brand, the assets and liabilities attached to the origin brand (Spielmann \& Williams, 2016). Thus, the corporate heritage identities of a place can have multiple roles, as they can encompass legal facets, material specificities, pedoclimatic conditions, higher-order capabilities such as workmanship, myths, rituals and many other representations that qualify the origin (Brunninge \& Hartmann, 2019; Charters \& Spielmann, 2014; Roscoe et al., 2013).

While a place can have its own corporate heritage identities, determined by unique characteristics (sometimes stereotypes), the value or the contribution of a place to a firm's corporate heritage identity depends in part on the cultural constraints imposed on the firm (Ballantyne, 2011). In certain places, the value of social heritage may be more important than technical heritage and vice versa. This suggests that the cultural heritage identities of places can be relatively invariant as well, being somewhat anchored but malleable. For example, for many French wineries, heritage means slow, centuries-long progress by monks, whereas for wineries in New Zealand it represents 40 years of technical experimentation. In both cases, the heritage 
identity is sourced from the history of the place and how the firm adapts to the environmental context in which it operates. This suggests that it is not exclusively the static history of the firm (e.g., "established since"; Burghausen \& Balmer, 2014a) that shapes the strength and distinctiveness of a firm's corporate heritage identity, but also the meaningfulness of history and heritage of the products being made and the meaningfulness of the history, culture, and heritage of the place where they are made and who makes them.

Extant literature on corporate heritage identity clearly highlights the importance of place. The comprehensive study of the British Monarchy (Balmer, 2011a, 2011b), the portrayal of Great Britain's oldest brewery (Berghausen \& Balmer, 2014, 2015) and one of China's oldest brewers (Balmer and Chen, 2017) emphasize, in cultural and territorial terms, the importance of place for corporate heritage identities. In tandem, research has also shown that a crucial element of corporate heritage branding relates to efforts by firms to source uniqueness from a place in order to improve their competitive position (Kavaratzis \& Ashworth, 2008). Due to intensified competition, firms have been found to rely increasingly on place branding to address their customers' perceived demand for differentiation between firms and corporate brands (Kavaratzis \& Kalandides, 2015).

In particular, place branding can 'form a 'unique selling proposition' influencing external visibility that reinforces an internal 'local identity"' (Colomb \& Kalandides, 2010, p. 175). This is achieved through unique stories associated with the people within the place. Such stories "hopefully create a compelling narrative, whereby identification with - and attachment to - the place is achieved among both external and internal audiences and, as a consequence, some form of place competitive advantage is gained" (Warnaby \& Medway, 2013, p. 346). Thus, place, as defined by the origin and as a narrative, can be expected to be reflected in the corporate heritage identity traits and strategies of wineries. Stories relating to the past, even when fabricated or 
"fibbed" (e.g., the myth of Dom Perignon in Champagne; see Charters \& Spielmann, 2014) and embedded in a place, contribute to corporate heritage identities (Brunninge \& Hartmann, 2019). Relatedly, as places can be branded, they also comprise identities (territorial, cultural, social, and ancestral), that can therefore be infused in and augment the multiple role identities of a firm's corporate heritage identity (Balmer, 2013; Balmer \& Burghausen, 2015; Balmer \& Greyser, 2002).

Yet, place identity is not a static construct; place identities are processes rather than outcomes, and thus influence identity-based place branding approaches (Kalandides, 2011). This suggests that place identities, like the corporate heritage identities of a firm, may be relatively invariant. Furthermore, place products should be regarded as dynamic concepts, composed as much from changing and competing narratives in and over time as from tangible and material elements (Warnaby \& Medway, 2013). A place can be very fixed and concrete to products (both literally and metaphorically), with a level of permanency spanning centuries, such as the wine regions in France and Italy, or just starting to gain recognition, such as regions less known for wine production (e.g., Denmark or the UK). Therefore, we propose that place identities are related to corporate heritage identity, in that they contribute to but also have the potential to shape the multiple role identities of a corporate heritage identity, which in turn are reflected in the corporate heritage identity of the firm within the place.

We speculate that place heritage identity can also then be shaped by the corporate heritage identities of the individual firms within the place. As such, place remains influential on how certain corporate heritage identity traits are conceived and appropriated by firms (c.f. Balmer \& Burghausen, 2015), as well as how corporate branding strategies are leveraged via multiple role identities (conferred by the place and the corporate brand) and how these identities remain relatively invariant. Corporate heritage identity traits may also partially mediate the influence of 
place on corporate strategies, because they contribute to simultaneously shaping the multiple role identities of the firm.

\subsection{Relevance and rationale for this study}

This study draws on seminal works outlining that "within one identity type for a particular company may reside several variations of that identity" (Balmer \& Greyser, 2002, p. 75). For example, products and businesses can be grounded in an origin (e.g., "Made in the US") and/or family heritage (e.g., the Walton family owns Walmart and is deeply embedded in Arkansas, USA). As such, we posit that where a business is set up, the narratives of those who run it and the type of products it makes (i.e., representative or not of a physical origin or family story) all play a role in defining a firm's corporate heritage identity.

Specifically, this research examines how the relative invariance of place guides managerial interpretations, actions, and initiatives directly influencing corporate heritage identity. To examine the phenomenon, we rely on research that outlines how geographic origin informs the corporate heritage identity of a firm (e.g., Balmer \& Greyser, 2006; Urde et al., 2007), on research defining the importance of multiple role identities for corporate heritage identity (e.g., Balmer, 2011a), as well as research on place (Kavaratzis \& Hatch, 2013; Warnaby \& Medway, 2013) and territorial branding (e.g., Charters \& Spielmann, 2014; Spielmann \& Williams, 2016).

Accordingly, we examine the corporate heritage identity of firms that specifically and explicitly identify with the geographical context or place in which they operate and market their products. We do so for two reasons. The first is because geographic places can, like firms, have heritage and identities. The identity of a place is often the result of mingled and highly related identities of the firms operating within the place, suggesting that firms which explicitly state their place of origin have multiple role identities. Likewise, and as demonstrated in the study of the

oldest brewers in the United Kingdom (Berghausen \& Balmer, 2014, 2015) and China (Balmer \& 
Chen, 2017), geographic places also have multiple role identities that can be bestowed on corporate brands and firms operating within them. As such, "corporate heritage footprints" can emerge at a macro-level in terms of cultures (Balmer, 2011a, p. 1386), or in the way things are done within a particular place (e.g., to produce and market beer), which are often inseparable from geographic origins.

The second reason we examine the corporate heritage identities of firms that explicitly identify with a geographical context is because while corporate brand history and heritage, just like origin history and heritage, cannot be changed (the past is the past and cannot be changed), they are relatively invariant. Importantly, the past can be amplified when it relates to the multitude of identity roles in the present that substantively and/or symbolically link the past, present and future (Balmer, 2013). For example, "corporate heritage footprints" may emerge at the micro-level in terms of architecture (Balmer, 2011a, p. 1386), which can be captured in the facilities a firm uses to produce and/or market a product. Although certain attributes of heritage may remain unchanged, the meanings ascribed to them can be mutable, emphasizing "both change and continuity" (Balmer, 2011a, p. 1387). Corporate heritage focuses on enduring heritage institutions and brands, which is different from the conventional association of heritage with spent institutions (Balmer, 2011a). Corporate heritage institutions "are repositories of meaningful, multiple heritage identities because of their apparent capacity to bestow multiple identities to individuals, families, groups, cultures, territories across the generations" (Balmer, 2013, p. 295), and they are, over time, likely to develop multiple role identities that are relatively invariant. Corporate heritage identities seemingly remain constant yet change. However, to date, further empirical work in relation to these arguments, particularly across contexts, is absent, and this therefore merits further scrutiny. 


\section{Methodology}

\subsection{Sample}

Family-owned wineries offer a relevant context to study corporate heritage identity because corporate brand heritage often emerges from the combination of family and business (Blömback \& Brunninge, 2013). To further understand if and how place influences their corporate heritage identity, this study is concerned with the experiences and views of those involved in firm management (similarly to Burghausen \& Balmer, 2014a; 2015). Depth rather than breadth was deemed important, with a focus on exploring and interpreting how corporate identity traits are construed and how they unfold in family-owned wineries. An interpretivist perspective and multiple case study design was ideal to reveal the motivations and rationale behind the decisions and practices of family businesses (Hamilton, Discua Cruz, \& Jack, 2017) that are prevalent in the wine industry. The comparative case study approach allows moving beyond a single case study within a place to a comparison of cases (as suggested by Balmer and Chen, 2015) and allows a richer perspective on how corporate heritage identity interacts with place and territorial brands.

Case studies of purposefully selected firms provided a systematic way of looking at processes and events, observing contemporary phenomena within real-life contexts, gathering and analyzing data, and reporting results (Leppäaho, Plakoyiannaki, \& Dimitratos, 2016). Furthermore, case studies from multiple countries were selected in order to provide more insight into place influence and help develop theory. Case studies represent an established approach within the methodological canon of corporate heritage identities (Balmer, 2011a; Burghausen \& Balmer, 2014a, 2015) and family business research (Melin et al., 2014).

Cases were selected based on where "the processes being studied are most likely to occur" (Denzin \& Lincoln, 2000. p. 370), which for this study were family-owned wineries in the 
Old (e.g., France and Italy) and New wine worlds (e.g., USA, Canada, UK and Denmark). Cases in diverse contexts added external validity (Riege, 2003) and helped better examine the complex dynamics in family businesses in the winemaking industry (Jaskiewicz, Combs, \& Rau, 2015; Spielmann \& Williams, 2016). As access to family businesses is hard to achieve (Winter, Fitzgerald, Heck, Haynes, \& Danes, 1998), businesses were approached on the basis of personal contacts or strong referrals. As there is no accepted ideal number of cases, the appropriate number of cases was determined by how much each added incrementally (Eisenhardt, 1989). The a priori variation in characteristics was achieved with seven cases. Table 1 summarizes the sample statistics and provides the acronyms for each case and category. Winery names have been changed due to a request for anonymity and confidentiality.

\section{INSERT TABLE 1 ABOUT HERE.}

\subsection{Questionnaire and Data Collection}

An interview questionnaire that would be comparable and usable in each country was established. Questions focused the discussion on understanding the history and the stories of the family in the business, the importance of the place for the business, as well as the dynamics of ownership, management, and business operations. The interview protocol considered the language and meaning of each question (Hamilton et al., 2017). The facets of corporate heritage identity were included as points of discussion: culture, philosophy, design, architecture (e.g., buildings and infrastructures), communication, products, groups and markets, and strategy (Balmer, 2011a). Informants also discussed retrospective and current place and identity narratives at length with the case writers in order to better assess the relevance of place in family businesses.

In addition to in-depth interviews, data collection included secondary data (e.g., 
brochures, company websites, industry publications, and newspaper articles) as well as participant observation (e.g., wine tours) when possible during 2014 and 2015. Such an approach is recommended to understand key aspects of corporate heritage identity (Burghausen \& Balmer, 2015). This overall data collection approach provided rich sources of evidence that allowed the authors and their collaborators to prepare, infuse, and use additional information at multiple points during the case edition as well as the case analysis process (Hamilton et al., 2017; Neergaard \& Leitch, 2015). The aim was to increase the transparency and validity of the methodological approach (Siggelkow, 2007) while providing methodological triangulation and more construct reliability.

Each written case study included a background of the wine industry context, the history of the company, organizational dynamics, family business dimensions (ownership, succession, and management), and the interviewees' perceptions regarding heritage and place qualities. Overall, the cases provided insights into the way family business owners or managers perceived the relevance of their origin and how they leveraged it in their corporate branding and strategies.

\subsection{Analysis}

Cross-case analysis grouped together common perspectives within the cases while permitting analysis on key issues and grouping together common items (Eisenhardt, 1989). The authors independently examined the data in interviews and observation notes, and then finalized the cases. Emerging perspectives were corroborated, resulting in an iterative process where cases were reviewed, discussed and debated, resulting in constant comparison methods and further triangulation and validity (Alvesson \& Skoldberg, 2000; Neergaard \& Leitch, 2015).

Next, data were grouped together around central identified themes. Manual methods of analysis were employed. Matrices were used to organize data and to improve comparisons across 
cases; field notes, margin notes, summaries, vignettes, diagrams, and mind maps were all used in the analysis (Miles, Huberman, \& Saldana, 2013). Finally, findings were "recontextualized" by comparing them to arguments in existing literature (Neergaard \& Leitch, 2015). The value of the relative invariance and multiple role identities in corporate heritage identity traits proposed by Balmer (2011a) and Balmer (2013) emerged strongly in the analysis and revealed a high level of integration with place, as well as downstream strategies.

\section{Findings ${ }^{1}$}

The examination, across contexts, of corporate heritage identity footprints at the macro and micro level, proposed by Balmer (2011a), revealed a symbiotic relationship of corporate heritage identities and place in the creation, development, and continuity of the corporate heritage identities of firms.

\subsection{Corporate Heritage Identity Traits and The Relative Invariance of Place}

\subsubsection{Culture}

The analysis revealed that culture traits of the family-owned wineries relate to place heritage in two distinct ways, based on their location (Old Word, New World). Old World cultures are predominantly defined by a product orientation that is homogenous across cases, focusing on established principles and methods related to traditional winemaking. For these firms, it is not uncommon to find more than five generations involved in the development of vineyards. As such, the concepts of family and generations are inherently part of the culture that defines their corporate heritage identity. The culture of the firm is based on how the family is native to the origin, the long-established and replicated processes they adhere to, and the respect

\footnotetext{
${ }^{1}$ A table with a detailed analysis is available online (Appendix 1, supplementary material)
} 
and compliance to tradition (both familial and geographical). For example, Zebra focuses on "continuity" and Regnier on "legacy". Thus, the way wine is produced remains fairly invariable. The Old World culture is cautious, with the main concern of firms focused primarily on communicating the established quality of their wines to new markets. The Old World wineries showcase a cultural identity and rationale for all wines and wine styles (Balmer, 2008). Such heritage identity traits appear to be stronger in countries such as France and Italy, where wine making has been a part of the landscape for far longer than it has in New World regions.

The New World cultures appear to be more heterogeneous - strongly characterized by exploration, experimentation, and an entrepreneurial approach of highlighting the distinctiveness of products (Appendix 1). These firms seek to enhance the way things were done in the past (e.g., processes often originating outside of their origin, but transposed in them). Integrating novel and nascent processes is part of the culture, because these firms seek to bring out the unique characteristics of the place in every product. For example, Siciliano seeks to adapt Italian winemaking traditions to the Ontario environment. Alternatively, Roberts adopts new ways of picking grapes and producing beyond the local Muscadine wine and Aksel seeks to identify grape varieties that are disease and weather resistant. The firms are highly driven to satisfy unmet market needs and capture niche markets, rather than depend on origin heritage to gain a competitive advantage. For example, Siciliano adapts their products to the diverse tastes in each province of Canada and Aksel focuses on a domestic market-only approach in Denmark.

\subsubsection{Philosophies}

In terms of philosophies, or the system of core beliefs that guides the firms' corporate heritage identity, the analysis revealed that place heritage had a deep yet distinctive influence in both locations (Appendix 1). Old World wineries focus on stewardship: they value the relevance 
of old, entrenched traditions, their linkage to the land or region, and they seek to maintain what their ancestors established. Consequently, they value actions that help to preserve corporate heritage identity, thus they encourage storytelling and immortalize family myths and heritage. Incoming generations are expected to learn the business from an agricultural perspective, thus they focus on oenology or specialized degrees that allow them to maintain the quality of their products and the richness of their land. Such core sets of beliefs fit a stewardship perspective in family firms (Davis, Allen, \& Hayes, 2010). Perpetuating process and respecting traditions are essential, as witnessed by the often very structured hierarchy within the firm, where family members occupy key managerial positions and become guardians of the corporate heritage identity. The family is expected to be part of the firm and to maintain a guardianship-based philosophy. Such an approach highlights the importance of a custodianship perspective of various generations of a family, concerned with protecting the institutional heritage that is part of the corporate brand or identity (Urde et al., 2007; Burghausen \& Balmer, 2015).

On the other hand, the philosophy of New World wineries is built upon key sets of values held by their much more recent founders. These values often relate to hard work, experimentation, and resilience. The founding generation provides insights and advice for successors, and is usually capable of participating in business decisions. Corporate changes are perceived as positive reactions to market conditions rather than as the potential betrayal of founding philosophies. While some New World wineries focus on preserving and heralding the values of their family heritage, others consider their wineries as a lifestyle that is shared by members of the firm. Such values also appear to have a strong influence on whether family members decide to get involved in the firm and which roles they accept. Opening up the firm to outsiders gives rise to creativity and a collective approach meant to identify new opportunities. These include experimenting with new types of wines and discovering the value that place brings, 
the pursuit of quality through attempts to win awards, expansion (beyond existing products), and innovation (introduction of diverse types of wines and varieties). As Appendix 1 shows, corporate heritage identity for New World wineries is driven by a philosophy that emphasizes adaptation, experimentation, and innovation.

\subsubsection{Design}

Examining the proprietary designs of the wineries (e.g., icons and logos) allowed the identification of how place heritage and place corporate heritage identity interacts with firm corporate heritage identity (Appendix 1). In Old World wineries, there is a greater sense of family heritage, as the family name is front and center on the design of the labels and other communication material. The design of icons and logos revolves around the family within the place or dissociating the family name from icons that might lead to place misidentification. For example, Regnier only uses metallic bottles (i.e., a luxury branding versus family-branding tactic) on champagnes it produces for other brands, even though the production of the metallic bottle is a unique firm competency. The logos, fonts, and icons are historical, timeless, and unchanged, regardless of trade areas and markets. Zebra has The Lion of Saint Mark in its logo, a strong ancient symbol of Veneto, its province of origin. The use of symbols in the design is driven by native obligations and historical observance for Old World wineries. Such an approach suggests that long-established family wineries can rely on the past to communicate corporate heritage (Balmer, 2011a; Hudson \& Balmer, 2013) related to origin.

New World wineries' icons and logos focus on nostalgic (firm-driven history) design and, thus, are more heterogeneous than those of the Old World. For example, the introduction and preservation of place or family-related designs may be particularly salient in immigrant families, for whom keeping a reminder of where they come from is important. Nostalgia is a relevant 
construct linked to emotional aspects of the past (Balmer, 2011a). In such cases, the design icons are often borrowed from other cultures or used to capitalize on cultural stereotypes imported from other origins. For example, Siciliano uses the Carretto, a symbol of Sicily, to evoke the Italian heritage of the founder, not because this horse-drawn carriage was once used at the winery. Alternatively, designs related to the origin of the firm are also found. For instance, the River name is related to the eponymous river in Cornwall. In this case, the firm is staking a claim on the place. For some, the design may showcase artefacts from existing businesses (e.g., the king chair at Siciliano) or commemorate special events relevant to the family (e.g., Papa Bliss at Roberts, Rosie's anniversary in River), which may evoke reminiscences or highlight achievements relevant for the family and firm in order to attempt to create myths and narratives that contribute to the firm's corporate heritage identity.

\subsubsection{Architecture}

Architectural heritage relates to physical buildings and facilities that can become integral to the corporate heritage identity of the firm. Our analysis revealed that Old World wineries have a more elaborate place-driven architectural heritage as compared to New World wineries, because they often capitalize on ancient architecture that was established before the firm (Appendix 1). In this sense, the place, irrespective of the firm's role in it, contributes to the corporate heritage identity of the firm. For example, Regnier owns real estate in adjacent villages, where its cellars can be found. These physical structures are comprised of three levels of aging cellars, which are among the deepest in Champagne (30 meters underground). These cellars are more than 150 years old, and each was built at a different era and then acquired by the Regnier family in the 1960s. Tunnels were then dug to connect the cellars and adapt the structure to the current needs of the firm. Regnier's strong architectural heritage existed even before the firm acquired it. 
Similarly, Zebra and Cinque ensure that the wineries they have acquired over the years preserve architecture related to wine production (e.g., cellars), which then reiterate and reinforce the firm's ancient winemaking origins and convey a sense of legacy or accrued past (Burghausen \& Balmer, 2018).

Alternatively, New World wineries' cellars or architectural structures are often their own creation or borrowed to suit the needs of the firm. The founders built premises in architectural styles that related to place in an effort to shape a sense of heritage related to place. As such, firms either opt for the architectural style preferred by the owners or an architectural style that is placespecific but designed and adapted specifically to their wine needs. For instance, the barrel cellar in Siciliano estates has been renovated in a Neo-Norman style and includes a 12.7-meter-long concrete table surrounded by 23 stainless steel chairs - Neo-Norman style is a firm preference and has nothing to do with Ontario. River has created a central visitor center using local craftsmanship to further support its place within the local English landscape. Finally, Roberts, in North Carolina, showcases the colonial family home that illustrates the agricultural heritage of a nine-generation farm in their advertising and labeling, although they did not begin growing grapes or making wine until 2009.

The Supplementary Materials Report (See Appendix 1) provides further details relative to corporate heritage identity-based traits. The analysis now turns to an examination of the corporate heritage identity strategies, which are also influenced by the previously discussed corporate heritage identity traits. 


\subsection{Corporate Heritage Identity Strategies: Relevance of Relative Invariance and Traits of Place}

\subsubsection{Overall Corporate Strategies}

The analysis of the evidence across wineries suggests an inherent heterogeneity of strategies and long-term perspectives in light of their origin. Specifically, there is a stronger reliance on the reputation of the territorial brand, the renown of the place-specific products, and the family for Old World wineries. Because these firms are not in an introductory phase of their life cycle, but more often in a maturity phase, they tend to focus more on reminding consumers and customers of the value of their products, as supported by strong territorial branding initiatives and firm legal protection (e.g., European trademark laws, reliance on territorial governance structures). For example, Regnier relies on the perception of champagne as a luxury product (as is the desired positioning by the overarching territorial brand; Charters \& Spielmann, 2014) and focuses on luxury consumption trends as indicators of industry health. Old World wineries have a more long-term historical perspective of their business, rooted in more conservative cultures and stewardship-driven philosophies. They are more cautious when it comes to making strategic moves and are also more likely to focus on one business, winemaking, in order to reap the reputational and heritage benefits of their established designs and architecture. For Old World wineries, who have developed their corporate brands and family reputation over generations, strategic alliances are important, and have mostly been established to confirm their role in their place. Examples of this are Regnier's relationship with international brand managers, fashion houses, and luxury restaurants (well known as associated industries in France) and Zebra's involvement with other Italian firms to promote the "Made in Italy" label overseas.

In contrast, New World wineries tend to face unique contextual issues that determine their corporate strategies and they often have less influential territorial brands, even if they have stricter or more complex legal and structural obstacles to face. For example, commercial 
winemaking has only been allowed in Denmark since 2000, due to EU regulations. While some of the New World wineries have introduced new products and are motivated to move beyond their local market, they are often stifled by legal restrictions or regulations (e.g., Roberts can currently only sell in North Carolina). The struggling, entrepreneurial, and resourceful aspects of New World wineries are consistent with their philosophy of adaptation and innovation.

Furthermore, these firms are being influenced by a regional and international demand to cater to diverse tastes via expanded product portfolios. Consequently, New World wineries diversification goes beyond the product and is often organized around additional business activities such as hospitality and retail, and in the specific case of Aksel, even a park-golf lane surrounding the vineyard. Here, the relationship between the architecture of firm facilities and corporate strategies is also obvious. In light of the many constraints they face, these wineries must adapt their offering to the environment in which they operate. Due to their nascent firm culture, these firms seek strategic alliances at a more local and regional level (e.g., River and the Cornwall region, Roberts and the North Carolina region, Aksel in the Funen area) to emphasize strong local ties and confirm their desire to be rooted in the origin. This is an indirect strategy by New World wineries to construct a territorial corporate brand in the hope of growing its value.

\subsubsection{Product and Market Strategy}

The analysis revealed that while all wineries had on average 4-5 product lines, the markets in which these companies operate varied - sometimes international or otherwise only within local territories (Appendix 1). The corporate heritage identities of all the firms are deeply defined by group membership of the origin in which they operate. All firms reported that they have close linkages to their local community via membership or involvement with local trade associations, government bodies (e.g., city, country, region), and governmental agencies (e.g., 
regulatory bodies such as the European Union for PDO status). These governance structures help the corporate brands to support a sense of community, communicate corporate social responsibility, and herald the place. As such, each place where these firms operate confers unique features on the corporate heritage identity. For example, the rules, mores, and culture of the Veneto territorial brand confer on Zebra specificities of their corporate heritage identity, which is evidenced in their designs.

However, in terms of product and market choices, the cases showed some significant differences. For the Old World wineries, market segments and offerings are generally stable, not changing much, with customers expecting certain features in their products to remain unchanged. The customers of these firms have become accustomed to the traditional, sometimes wide, but not often deep product lines. ${ }^{2}$ Old World wineries rarely replace products, as this would be violating the edict of tradition and perpetuation of seminal products such as place specialties (e.g., dry Champagne for Regnier). Alternatively, New World wineries use an explicit co-creation approach, in which customers are invited to help develop new products adapted to their preferences. This strategy relates directly to fewer constraints from an overarching territorial corporate brand, but also to a culture that is focused on market orientation. New World Wineries are more intent on changing the packaging, creating more accessible or more upscale product lines, or different blends than Old World wineries. However, when they introduce a new product, they tend to remove an existing one from their line, assuming that this one has fallen out of favor. Overall, the product and market strategies in the New World are fluid and flexible.

\footnotetext{
${ }^{2}$ Wide product lines would be numerous different wines, each made from different grape varieties. Deep product lines would involve, for example, many different versions of each wine made with a grape variety, such as many different vintages of the same Merlot-based wine. (Thach \& Charters, 2016; Charters \& Spillman, 2016)
} 


\subsubsection{Communication}

Whilst in all cases, external communication serves to herald firm milestones, product offerings, and efforts to cater to the demands and concerns of society (e.g., environmental accreditations), there are distinctions in the ways the Old World wineries and New World wineries achieve this (Appendix 1). Old World wineries capitalize on their long business tenure by informing consumers of recent events or new products, and also by inspiring discussions with wider audiences through an online presence, (e.g., newsletters, blogs, social media). They seek to introduce and affirm their long-established corporate heritage identity culture and philosophy to new customers and reinforce their contact and positioning with existing customers (Balmer, 2011a). In all communication channels, the message transmits what makes the firm's products unique (i.e., history, family, products, accreditation, place, milestones and awards), usually with a dedicated section on place corporate heritage and how the firm is important in defining the corporate heritage of the place, but remains minimal, descriptive, one-way, and less interpersonal. Old World wineries rely less on consumers communicating with the firm and more on consumers communicating with each other about the firm and territorial brand initiatives (i.e., professional associations such as the CIVC in Champagne) that speak about their products.

In Old World wineries, the diverse narratives around place persist, and create a sound platform to communicate place over decades and relate it to corporate heritage identity. Narratives create further associations between place and corporate heritage identity. For instance, corporate heritage identity in Old World wineries benefits from "material persistence" in place, which relates to material presence embodied in landscape and built environments (Cresswell \& Hoskins, 2008, p. 409). Such persistence relates to both material and meaning aspects focusing on historical processes (c.f., Warnaby, Medway, \& Bennison, 2010). This can be noticed in spaces where the materiality of vineyards and wineries are evident, such as in ancient cellars and 
historical buildings, and where "meaningful association" (Cresswell \& Hoskins, 2008, p. 393) in terms of fine wine production over decades is made. Different stories, including those of winemaking families, communicate a positive image about their place. Old World wineries accentuate the beauty of long-established wine regions, a message that is buoyed by the communication of the established territorial corporate brands.

Alternatively, New World wineries use extensive and interactive websites to highlight family farming heritage, provide a strong description of family and business history and showcase alliances, community relationships, products or innovations (e.g., holiday gifting propositions). Information about products is very detailed, with the core messages being the uniqueness of the firm products, methods, and offers. The main objective is to stimulate immediate sales. Consequently, robust e-commerce platforms have evolved over time, providing both local and regional offers. Furthermore, these firms communicate about their related offers, such as regular tours of their premises. These activities are usually led by family members, further allowing the firms to communicate their history, highlight the relevance of family in the company, promote their achievements and milestones, and encourage interaction between consumers and family members. It is also not uncommon for New World wineries to communicate their involvement in local wine festivals or markets via leaflets and brochures distributed in tourist destinations around their region. Thus, the communication strategies of these firms appear to be more educational, interactive, and independently driven, versus collective efforts that would otherwise be organized by the territorial brand. New World wineries appear to capitalize rapidly on multiple place narratives. The view of place as a social construction fits well with this view, as a place is conceptualized as offering more than one product.

The analysis revealed that connection between place and corporate heritage identity has a different meaning in the Old World wineries compared to the New World wineries, with different 
narrative stories relating wine and corporate heritage identity, thus guiding strategies. In Old World wineries, place associates with corporate heritage identity through the diverse multitude of narratives around materiality/physical elements, practices/structures of social interactions, regulating institutions, and systems of representations. Here, winemaking families are surrounded by intentional and unintentional reminders of where they are, and their corporate heritage identity reflects such contexts. In contrast, New World wineries have to create or link their story to already established place narratives. They rely strongly on stories linked to their ancestry in old wine-producing regions to start creating narratives around practices and the family element of corporate heritage identity. Compared to Old World wineries, where families are already part of the narratives of winemaking, New World wineries' families have to borrow existing stories from the place (e.g., Cornwall craftsmanship and weather, North Carolina farming heritage and associations).

Furthermore, compared to Old World wineries, where the process of corporate brand formation around winemaking is mature and stable, New World wineries engage actively in the corporate brand formation process to associate their story with a narrative around wine. The interconnection between winemaking families and diverse place dimensions in the formation of corporate heritage identity is evident in the narratives used (Kalandides, 2011). Materiality is linked to promoting the properties of the land where vineyards are planted. Due to the early diversification of New World wineries into related industries (e.g., tourism, retail, golf parks), each place gradually becomes a context of relations (economic, social and others), practices (e.g., vineyard tours), and institutions (laws and regulations about their functioning).

In contrast, in the Old World wineries, the creation and continuity of the relationship between place and corporate heritage identity appear to be linked to the involvement of family members over a long period of time. The narratives of the winemaking families in Old World 
wineries are closely linked with the place. Winemaking families steward the relationship of place and corporate heritage identity by engaging in understanding and promoting physical/material aspects (terroir, land features, historical architecture), participating in key institutions (longestablished associations) and representing the symbolic nature of their places in their products. Stewardship is supported by transmitting a multitude of stories over generations. Corporate heritage identity is built on stories, and family members have often worked at crafting many stories related to place for decades. Such an approach relates to the substantive and/or symbolic exchange/inheritance of corporate heritage across/between generations of stakeholders that link the past, present and future, referred to as intergenerational continuity, a fundamental characteristic of corporate heritage (Balmer, 2013, Balmer \& Burghausen, 2019).

As a result, winemaking families in Old World wineries do not seem to try to create an old story or narrative because it already exists. In these wineries, winemaking families already have the diverse stories around place linked to their corporate heritage even before new generations enter the business. In doing so, long-established winemaking families become central actors and stakeholders in associating place with corporate heritage identity. The Supplementary Materials Report (see Appendix 1) contains further details relative to corporate heritage identitybased strategies.

\section{Discussion}

The principal thesis of this article was to study the multiple role identities and relative invariance (Balmer, 2011a; Balmer, 2013) of corporate heritage identity by examining the interaction of a firm operating in a place, and this across cultures. The results of our qualitative comparative case study in family-owned wineries support the notion that corporate heritage identity confers identities on people, places, communities, and cultures (Balmer, 2011a). Our 
findings extend understanding by showing that, across contexts, the relative invariance of place informs different interpretations and reconciliations of corporate heritage identity traits (e.g., cultures, philosophies, design, and architecture) and influences firm strategies, both directly and indirectly, through corporate heritage identity traits and their connection to place. Therefore, the findings demonstrate that the interaction of place and firm leads to the multiple role nature of corporate heritage identities. Specifically, the results add depth to our understanding of the important interaction of place and firm corporate heritage identities and the roles of multiple role identities and relative invariance in defining corporate heritage traits and strategies (as per Balmer \& Chen, 2017; Balmer, 2011a, Balmer, 2011b; Urde et al., 2007; Balmer et al., 2006; Balmer \& Burghausen, 2019) by identifying place as a nexus for corporate heritage identity. Our findings support that indeed, multiple role identities and relative invariance lead to augmented, richer, and more relevant corporate heritage identities (as suggested by Balmer, 2013); however, this study extends understanding by providing cross-cultural evidence of this in the wine industry, which is considered a highly fragmented context (Tyler et al., 2018). The results support that corporate heritage identity traits and strategies are shaped by place corporate heritage and the corporate heritage identities of other firms within the place in which they are conceived, and vice versa. However, the findings extend understanding by uncovering the fact that there is also an obvious uniqueness of the corporate heritage identity of a place, which firms (especially family businesses, as examined in this study) attempt to capture in order to distinguish their products, to make their offerings special and distinctive, and to stand out from the competition (as suggested by Brunninge \& Hartmann, 2019). To illustrate our findings, this study proposes a model of Corporate Heritage Identity Across Cultural Contexts (Figure 1). This conceptual model serves as a framework to study the influence of multiple role identities and relative invariance of place and corporate heritage identity across contexts. 


\section{INSERT FIGURE 1 ABOUT HERE.}

The cross-cultural findings presented here (Figure 1) build on prior research in marketing by bridging the corporate heritage identity literature (e.g., Balmer, 2009, 2011a; Balmer \& Burghausen, 2017) with that of the territorial branding (e.g., Charters \& Spielmann, 2014; Spielmann \& Williams, 2016) and place literature (e.g., Kalandides, 2011; Warnaby \& Medway, 2013; Kavaratzis \& Kalandides, 2015). Differentiating between Old World and New World types of places allows for a better understanding of how place and territorial corporate brands shape and contribute to corporate heritage identity; as such, the findings framed in the proposed model (Figure 1) add volume and depth to corporate heritage identity conceptualization and theory (Balmer et al., 2006; Balmer, 2011a; Bessiere, 1998). Moreover, the model confirms how the multiple role identities and the relative invariance of firms interact with those of the place (Balmer, 2011a).

The empirical findings suggest that the place of a business, sometimes coupled with the origin of a family and a territorial brand, can determine if and how the business reacts to opportunities and crafts strategies (Figure 1). Clearly, the heritage of the family (e.g., native versus immigrant), the place's relationship to the wine industry (e.g., well-established versus nascent), and the management perspective (e.g., stewardship versus entrepreneurship) overlap and become integrated into the traits that define the firm's unique corporate heritage identity (Appendix 1). These are corporate brand facets that convey notions of time and place in ways that become meaningful to consumers (Brunninge \& Hartmann, 2019). Furthermore, the place and corporate heritage identity traits in which businesses plant their vineyards and produce their wines shape the trajectory of the firms' corporate heritage identity strategies. 
This context, where the family, firm, and place become inseparable over time, supports a unique corporate heritage identity based on multiple role identities. Whereas wineries in the Old World context appear to steward and leverage the value of the relative invariance of corporate heritage identities, in the New World Wineries, the multiple role identities associated with diverse actors in place allow the invention of corporate heritage identity related to place. Thus, while Old World wineries may benefit from a bonafide corporate heritage identity, those in the New World may have shaped, in effect, an invented or fabricated corporate heritage (Brunninge \& Hartman, 2019). Such fabrication relies on links with history, heritage or past events in a place, resulting in the construction or invention of a heritage narrative. Such an approach arises as New World wineries link their corporate identity traits and strategies to the way new consumers associate heritage with being authentic, highlighting aspects related to places (e.g., the natural elements, the relationship to place, Aboriginal grapes and experimentation) relevant for new markets and generations. In doing so, they have relied on the multiple role identities (Balmer, 2013) associated with place. For such companies, corporate heritage identity is constructed entirely in the present (Brunninge \& Hartman, 2019). As such, the model (Figure 1) shows the importance of relative invariance of place in the conceptualization of corporate heritage identity, thereby building on existing knowledge of multiple role identities with a cross-cultural examination.

The findings further highlight that the concept of corporate heritage identity is, in part, a social construction, as it is unique to each cultural context where the firm operates, and in this sense relatively invariant (Balmer, 2011a). Strong corporate heritage identity can have a corporate purpose (easier to recognize) but also helps confer identities on places - suggesting that they do indeed take on multiple roles (Balmer, 2013). For example, the strong corporate heritage identity of the Veuve Clicquot firm helps confer the identity of luxury and exception on 
Champagne, the place in addition to the products it creates (sparkling wines). What clearly distinguishes the cases examined for this research is the historical value of place (versus the firm or the family history) that they express through their corporate heritage identity traits. For example, Old World wineries reap the benefits of well-established and often well-known origins (e.g., Champagne, Veneto, Piacenza) and their carefully embedded established territorial brands. While there are benefits to operating within an established origin (e.g., more valuable and enduring place-product associations), these firms are also limited in terms of their flexibility, due in part to established origin mores and strong territorial brands that impose stricter rules and social norms.

Therefore, and as per Charters and Spielmann (2014), the results show that the overarching origin corporate heritage can be highly influential in shaping the firm's corporate heritage identity. One could argue here that the corporate heritage identity of the region, established by the collective efforts of other firms, can determine the corporate heritage identity of the firm. Heritage can impart a "sense of security" (Balmer, 2011a, p. 1383) and in established regions known for certain products, heritage can also define the corporate heritage identity of firms. Alternatively, New World wineries often develop their corporate heritage identity in tandem with that of the origin heritage. They are active in the development of the place heritage relative to their product category. Less bound by history, these firms can more easily define the level and type of influence that place has on their corporate heritage identity, yet they reap fewer benefits from a territorial brand.

Interestingly, this study also reveals the importance of consumers in the appreciation of corporate heritage identity, because they are relatively invariant. Recent research has examined the meaningfulness of corporate heritage identity for consumers across generations (Balmer \& Chen, 2015), how it defines consumer satisfaction (Balmer \& Chen, 2017) and even national 
identity (Balmer \& Chen, 2016). What this research does is examine the meaningfulness across cultures, showing how the consideration of consumers can influence corporate strategies, depending on the cultural context. As such, our research also speaks to contemporary research on how heritage can be a managerial stewardship disposition (Burghausen \& Balmer, 2015). Whereas Lamertz, Foster, Coraiola, \& Koezen (2016) outline how heritage elements that had been left by the wayside by established entities now inform the collective corporate heritage identities of new firms within a region, we examine how established or nascent cultures and their established or nascent corporate heritage identity interact with the individual firm's corporate heritage identity. As such, the relative invariance of place, in addition to time (Balmer, 2011a), is brought to light in this study.

The findings also suggest a recurring theme in the material substrate that interconnects the different elements of both Old World and New World wineries, providing further empirical support to the view of Kalandides (2011), Warnaby \& Medway (2013) and Kavaratzis \& Kalandides (2015). It is the materiality of the wine-producing region and the regulatory systems (established and nascent) that give place its continuity, while practices (established, borrowed or experimental winemaking techniques) and social interaction (with other wine producers or customers) provide room for change and progress. Kalandides (2011) suggests that these elements, materiality, institutions, and practices are so interwoven in place that it is impossible to dissociate them. Findings reveal that the interconnection of materiality, practices, institutions, and representations weaves a net of co-existing narratives that create a strong relationship between place and corporate heritage identity. In both established or young wineries, the people in each region and their practices highlight a multitude of stories that exist simultaneously. It is this coexistence of diverse narratives that influences the corporate heritage identity of wineries. Supporting the views of Medway, Swanson, Delpy, Neirotti, Pasquinelli, \& Zenker (2015), this 
study helps address the concerns of skeptics on the relevance of place to understand the world.

Finally, the results also shed light on the specific dimensions of place heritage interacting with corporate heritage identity, making the distinction between land and people (i.e., family) as contributors. The findings build on existing research on the importance of place in corporate heritage identity (Brunninge \& Hartmann, 2019; Urde et al., 2007) and add volume and specific depth to the current understanding of this essential dimension of corporate heritage identity. For example, for Old World wineries, the name of the family and its role in the region is an integral part of the corporate heritage identity. Keeping the family established within the place, as a stable reference and a symbol of longevity, is essential to the firm's corporate heritage identity. In New World wineries, the immigrant story and/or the innovator story are key to the evolving corporate heritage identity. The founders of these wineries wrestled the elements, overcame hostile environments, or faced complex regulations to conquer their origin. As such, this research confirms the multi-modal dimensions and the multiple role identities of corporate heritage identity (Balmer, 2011a; Balmer, 2013; Balmer \& Burghausen, 2015; Burghausen \& Balmer, 2014a; 2015).

\section{Conclusions}

Overall, the results of this study demonstrate the role and implications of place on corporate heritage identity definition and construction. Thus, it contributes to the ever-growing body of work on corporate heritage identity definition (Balmer, 2001a; 2011b). This research further makes the distinction between place heritage and the territorial brand more germane. Whereas place heritage, what was present in the place before the firm existed, is adopted by a firm and integrated into traits, a territorial corporate brand is the result of firms existing in a place and promoting their existence through the place, which both directly and indirectly influences the 
corporate heritage identity of firms (Figure 1). The resulting interpretation of these findings is that place is not superficial to the conceptualization of corporate heritage identity but an integral component.

This study offers several contributions. First, this research builds upon Balmer's (2011a; 2013) notions of relative invariance and multiple role identities of firms by examining how these contribute to place corporate heritage identities and vice-versa. Corporate heritage brands remain relatively invariant and remain meaningful through time (Balmer \& Chen, 2017; Balmer, 2011a, Balmer, 2011b; Urde et al., 2007; Balmer et al., 2006; Balmer \& Burghausen, 2019). We add to prior research by showing the role of place heritage and identity in contributing to the invariance of corporate heritage identities and also as a source of meaningful corporate heritage identity traits. This research consequently provides more depth to these two seminal notions (i.e., relative invariance and multiple role identities) of corporate heritage identities and allows for a more finetuned appreciation of these phenomena through the lens of place.

Second, this research supplements and confirms current work on corporate heritage identity (e.g., Balmer, 2011a; Blömback \& Brunninge, 2013) and the relevance of place in the definition and appropriation of corporate heritage identity traits by firms. Beyond "marketing the places of the past" (Balmer, 2011a, p. 1383), the results of this study add to existing literature on the power of places as embedded and inseparable parts of corporate heritage identity traits that nourish but are also nourished by region and place identities (c.f. Balmer et al., 2006; Balmer \& Chen, 2015). It also reinforces existing research on how a place is capable of both adding distinctiveness to corporate heritage identity brands and shaping firms' marketing strategies.

Third, the results add to the invariance notion of corporate heritage identity and corporate heritage brands and specifically examine the invariance of place. The identities of places can develop and evolve, just as they can remain stable and continuous. Specifically, corporate 
heritage identities can communicate a notion of place in ways that become highly relevant for consumers (Brunninge \& Hartmann, 2019). By using a cross-cultural case analysis, we provide a fine-tuned analysis of the change and continuance identities relative to a place and how these aid and benefit individual firm corporate heritage identity and vice versa. We also provide one of the first multi-country and cross-cultural analysis of corporate heritage identities and corporate heritage brands (as called for by Balmer \& Burghausen, 2015; Balmer \& Chen, 2015). In addition, this study builds on prior research on managerial stewardship dispositions (e.g., Burghausen \& Balmer, 2015) and valuable corporate heritage implementation strategies (Burghausen \& Balmer, 2014a; Balmer \& Gray, 2003) by examining it across cultural contexts.

Overall, this article relies on and supports research on place and corporate heritage identity (Balmer, 2011a; 2011b), and in doing so confirms the importance of place and culture, therefore highlighting the multiple role nature of corporate heritage identities. We extend this stream of research and argue that especially for corporate brands that are bounded to their origins (Spielmann, 2014), the relationship between the corporate heritage identities of the firms and the corporate heritage identities of the place is a defining modality.

\subsection{Managerial Implications}

The overarching managerial implication from this research is that firms considering developing a corporate heritage identity should first examine the corporate heritage identities of the place, of other firms within the place, and then the place heritage of where they operate and whether a territorial brand exists that they can capitalize on. This study highlights that within the nature of heritage place brand and heritage product brand, there are mutabilities: things that we expect to be anchored and unchanged do actually change through time. Therefore, with our findings we can extend current understanding of where agency lies in corporate heritage branding 
- we find that agency is not distributed solely within a firm, but rather it is distributed across a community, anchored in a place and across actors (as suggested by Brunninge \& Hartmann, 2019). This has implications for how managers connect with and work with other agencies to leverage not only the value of their corporate brands and their products but also of the place itself, because that exponentially increases collective value and collective action.

Indeed, there is a clear difference between having corporate heritage identities and using them strategically (Urde et al., 2007). As Charters \& Spielmann (2014) and more recently Brunninge \& Hartmann (2019) suggest, within the discourses of territorial brands exist mythical and historical cultures that may help to better contribute to the positioning of a firm's corporate heritage identity. It is through place-driven narratives that unique selling propositions can arise. The results of this study reveal that the role of place and the collective and distributed nature of producing a corporate brand around place may be particularly pertinent to some industries.

In light of this study's focus on family-owned wineries, the managerial implications are tied more specifically for these firms. First, family firms seeking to identify and define their corporate heritage identity may want to consider incorporating components of the place. For instance, fruit and tobacco firms that have been transformed into wineries can use agricultural know-how and historical clout as key facets of their corporate heritage identity. Likewise, focusing the family firms' corporate heritage identity on entrepreneurial activities could be another interesting strategy to adopt. Expounding on family firms' entrepreneurial legacy (Jaskiewicz et al., 2015; Hammond, Pearson, \& Holt, 2016) may further strengthen a unique corporate heritage identity over time. Such uniqueness may gradually shape and reflect intergenerational continuity, guiding the symbolic exchange/inheritance of corporate heritage across/between generations of stakeholders, linking the past, present, and future (Balmer, 2013, Balmer \& Burghausen, 2019). For example, American wineries can focus on the American dream 
and Horatio Alger-styled stories to highlight their surmounting and subsequent management of new, unchartered territories in winemaking. This style of firm corporate heritage identity speaks to the place as well as to the entrepreneurial know-how of the family.

Second, wineries in very well-established places may wish to focus on their definition of tradition - relating heritage in terms of the past as well as its relevance in the present and to the future (Balmer, 2011a). Tradition can be a key cornerstone for future innovation, yet it brings with it expectations that have to be fulfilled. Tradition does not have to mean dusty and oldfashioned; rather it can reference continuity of essential firm traits and strategies, adapted to the modern world (Balmer \& Burghausen, 2019). In doing so, their corporate heritage identity would benefit from multiple role identities and feature relative invariance (Balmer, 2011a). Examples could include producing wines using established, perhaps even historic methods, but placing the product in innovative packaging. The findings of this study suggest that tradition, as well as novelty, provides unique opportunities to market products.

\subsection{Limitations and future research}

This research has some limitations. First, the sample of comparative cases is small and the sampling logic would have been stronger if a broader sample of cases from countries with significant levels of production had been included, such as Australia, Argentina, Chile, Spain, and Germany. Nonetheless, the sample consists of large and small family firms that produce wine from both well-established and more novel places, which allows for a good overview of extreme theoretical categories, thus suggesting theoretical relevance (Eisenhardt, 1989; Yin, 2003).

Second, all of the cases are in a single industry, thus research on firms from other industries or across industries, where defining characteristics of corporate heritage including omni-temporality, intergenerational continuity, and augmented role identities (see Balmer, 2011a, 
2013; Burghausen and Balmer, 2014a; Urde et al., 2007) can be examined in relation to place, should be conducted in order to validate our findings (e.g., cheese, coffee, artisan products, glassmakers, tourism-related industries). Finally, other methods (e.g., survey data, financial analyses, archival records, historical approaches) could be used in future studies to test the relationship between traits of origins and territorial brands, corporate heritage identity traits of firms, and firms' corporate heritage identity strategies. Further studies around the world that focus on place as nexus in corporate heritage identity can support, challenge and extend the results of this study and advance understanding in the growing and fascinating field of corporate heritage identity. 


\section{References}

Alvesson, M., \& Skoldberg, K. (2000). Reflexive methodology: New vistas for qualitative Research. London: Sage.

Ashworth, G. J. (2013). From history to heritage-from heritage to identity, in G.J. Ashworth and P.J. Larkham (Eds.), Building a new heritage: Tourism, culture and identity in the new Europe, London: Routledge, 13-30.

Ashworth, G. J., \& Kavaratzis, M. (2011). Why brand the future with the past? The roles of heritage in the construction and promotion of place brand reputations. In F. M. Go and R. Govers (Eds), International place branding yearbook 2011, London: Palgrave Macmillan, 25-38.

Ballantyne, D. (2011). Sustaining the promise of terroir: the case of the Central Otago Wine Region. 6th Academy of Wine Business Research Conference, 9-11 June, Bordeaux, France.

Balmer, J. M. T. (2008). Identity-based views of the corporation: Insights from corporate identity, organisational identity, social identity, visual identity, corporate brand identity and corporate image. Eur J of Mark, 42, 879-906.

Balmer, J. M. T. (2009). Scrutinising the British Monarchy: The corporate brand that was shaken, stirred and survived. Manag Dec, 47, 639-675.

Balmer, J. M. T. (2011a). Corporate heritage identities, corporate heritage brands and the multiple heritage identities of the British Monarchy. Eur J of Mark, 45, 1380-1398.

Balmer, J. M. T. (2011b). Corporate heritage brands and the precepts of corporate heritage brand management: Insights from the British Monarchy on the eve of the royal wedding of Prince William (April 2011) and Queen Elizabeth II's Diamond Jubilee (1952-2012). J of Brand Manag, 18, 517-544.

Balmer, J.M.T. (2013). Corporate heritage, corporate heritage marketing, and total corporate 
heritage communications: What are they? What of them? Corp Commun, 18, 290-326.

Balmer, J. M.T. (2017). Corporate heritage, corporate heritage marketing, and total corporate heritage communications: What are they? What of them? In J. M. Balmer (Ed), Foundations of Corporate Heritage, London: Routledge, 89-129.

Balmer, J. M. T. \& Burghausen, M. (2015). Explicating corporate heritage, corporate heritage brands and organisational heritage. J of Brand Manag, 22, 364-384.

Balmer, J. M., T. \& Burghausen, M. (2019). Marketing, the past and corporate heritage. Mark Theor, forthcoming. https://doi.org/10.1177/1470593118790636

Balmer, J.M.T. \& Chen, W. (2015). Corporate heritage brands in China. Consumer engagement with China's most celebrated corporate heritage brand-Tong Ren Tang: 同仁堂. J of Brand Manag, 22, 194-210.

Balmer, J.M.T. \& Chen, W. (2016). Corporate heritage tourism brand attractiveness and national identity. J of Product \& Brand Manag, 25, 223-238.

Balmer, J.M.T. \& Chen, W. (2017). Corporate heritage brands, augmented role identity and customer satisfaction. Eur J of Mark, 51, 1510-1521

Balmer, J. M.T. \& Gray, E. R. (2003). Corporate brands: What are they? What of them? Eur J of Mark, 37, 972-997.

Balmer, J.M.T. \& Greyser, S.A. (2002). Managing the multiple identities of the corporation. California Manag Rev, 44, 72-86.

Balmer, J. M.T., \& Greyser, S. A. (2006). Corporate marketing: Integrating corporate identity, corporate branding, corporate communications, corporate image and corporate reputation. Eur J of Mark, 40, 730-741.

Balmer, J.M.T., Greyser, S.A. \& Urde, M. (2006). The crown as a corporate brand: insights from 
monarchies, J of Brand Manag, 14, 137-61.

Banks, G., \& Overton, J. (2010). Old world, new world, third world? Reconceptualising the worlds of wine. $J$ of Wine Res, 21, 57-75.

Bessiere, J. (1998). Local development and heritage: traditional food and cuisine as tourist attractions in rural areas, Sociol Ruralis, 38, 21-34.

Blömback, A. \& Brunninge, O. (2013). The dual opening to brand heritage in family businesses. Corp Commun: Int J, 18, 327-346.

Brunninge, O., \& Hartmann, B. J. (2019). Inventing a past: Corporate heritage as dialectical relationships of past and present. Mark Theor, forthcoming.

\section{https://doi.org/10.1177/1470593118790625}

Burghausen, M., \& Balmer, J. M. T. (2014a). Corporate heritage identity management and the multi-modal implementation of a corporate heritage identity. J of Bus Res, 67, 2311-2323.

Burghausen, M. and Balmer, J.M.T. (2014b) Repertoires of the corporate past: Explanation and framework. Introducing an integrated and dynamic perspective. Corp Comm: A Inter Journ, $19,384-402$.

Burghausen, M. \& Balmer, J.M.T. (2015). Corporate heritage identity stewardship: A corporate marketing perspective. Eur J of Mark, 49, 22-61.

Burghausen, M., \& Balmer, J. M. T. (2017). Corporate heritage identity stewardship: A corporate marketing perspective. In J. M. T. Balmer (Ed), Foundations of Corporate Heritage, London: Routledge, 169-213.

Charters, S., \& Spielmann, N. (2014). Characteristics of strong territorial brands: The case of champagne. J of Bus Res, 67, 1461-1467.

Chrisman, J. J., Sharma, P., \& Taggar, S. (2007). Family influences on firms: An introduction. $J$ 
of Bus Res, 60, 1005-1011.

Clarke, O. (2015), The History of Wine in 100 bottles: From Bacchus to Bordeaux and Beyond, Toronto: Sterling Epicure.

Cormack, P. (2008). True stories of Canada: Tim Hortons and the branding of national identity. Cult Socio, 2, 369-384.

Cresswell, T., \& Hoskins, G. (2008). Place, persistence, and practice: evaluating historical significance at Angel Island, San Francisco, and Maxwell Street, Chicago. Annals of the Assoc of Am Geogr, 98, 392-413.

Davis, J. H., Allen, M. R., \& Hayes, H. D. (2010). Is blood thicker than water? A study of stewardship perceptions in family business. Entrep Theory and Pract, 34, 1093-1116.

Denzin, N., \& Lincoln, Y. (2000). The SAGE handbook of qualitative research (2nd ed.). Thousand Oaks, CA: Sage.

Eisenhardt, K. M. (1989). Building theories from case study research. Acad of Manag Rev. 14, 532-550.

Foster, W. M., Suddaby, R., Minkus, A., \& Wiebe, E. (2011). History as social memory assets: The example of Tim Hortons. Manag \& Organ Hist, 6(1), 101-120.

Hamilton, E., Discua Cruz, A., \& Jack, S. (2017). Re-framing the status of narrative in family business research: Towards an understanding of families in business, J Family Bus Strat, 8, 3-12.

Hammond, N. L., Pearson, A. W., \& Holt, D. T. (2016). The quagmire of legacy in family firms: Definition and implications of family and family firm legacy orientations. Entrep Theory and Pract, 40, 1209-1231.

Hudson, B. T. (2011). Brand heritage and the renaissance of Cunard. Eur J of Mark, 45, 15381556. 
Hudson, B. T., \& Balmer, J. M. T. (2013). Corporate heritage brands: Mead's theory of the past. Corp Comm: An Inter Journ, 18, 347-361.

Jaskiewicz, P., Combs, J. G., \& Rau, S. B. (2015). Entrepreneurial legacy: Toward a theory of how some family firms nurture transgenerational entrepreneurship. J of Bus Ventur, 30, 2949.

Kalandides, A. (2011). The problem with spatial identity: revisiting the "sense of place." J of Place Manag and Dev 4, 28-39.

Kavaratzis, M., \& Ashworth, G. (2008). Place marketing: how did we get here and where are we going? J of Place Manag and Dev, 1, 150-165.

Kavaratzis, M., \& Hatch, M. J. (2013). The dynamics of place brands: An identity-based approach to place branding theory. Mark Theory, 13, 69-86.

Kavaratzis, M., \& Kalandides, A. (2015). Rethinking the place brand: the interactive formation of place brands and the role of participatory place branding. Environ and Plan A, 47, 13681382.

Kim, Y., \& Gao, F.Y. (2013). Does family involvement increase business performance? Familylongevity goals' moderating role in Chinese family firms. J of Bus Res, 66, 265-274.

Lamertz, K., Foster, W.M., Coraiola, D.M. and Kroezen, J. (2016). New identities from remnants of the past: An examination of the history of beer brewing in Ontario and the recent emergence of craft breweries. Bus Hist, 58, 796-828.

Leppäaho, T., Plakoyiannaki, E., \& Dimitratos, P. (2016). The case study in family business: An analysis of current research practices and recommendations. Family Bus Rev, 29, 159-173.

Lowenthal, D. (1998), Fabricating heritage. Hist and Mem, 10, 5-24.

Macdonald, S. (2006). Undesirable heritage: Fascist material culture and historical consciousness in Nuremberg. Int J of Herit Stud, 12, 9-28. 
Medway, D., Swanson, K., Delpy Neirotti, L., Pasquinelli, C., \& Zenker, S. (2015). Place branding: are we wasting our time? Report of an AMA special session. J of Place Manag and Dev, 8, 63-68.

Melin, L., Nordqvist, M. \& Sharma, P., (2014). The SAGE handbook of family business, Thousand Oaks, CA: Sage.

Miles, M. B., Huberman, A. M., \& Saldana, J. (2013). Qualitative data analysis: A methods sourcebook. Thousand Oaks, CA: Sage.

Moingeon, B., \& Ramanantsoa, B. (1997). Understanding corporate identity: the French school of thought. Eur J of Mark, 31, 383-395.

Neergaard, H., \& Leitch, C. M. (2015). Handbook of qualitative research techniques and analysis in entrepreneurship. Cheltenham: Edward Elgar Publishing.

Patterson, T., Buechsenstein, J., \& Freeman, N. (2018). Wine and place: A terroir reader. Oakland, CA: Univ of California Press.

Riege, A. M. (2003). Validity and reliability tests in case study research: a literature review with "hands-on” applications for each research phase. Qualitative Mark Res: An Int J, 6, 75-86.

Roscoe, P., Discua Cruz, A, \& Howorth, C. (2013). How does an old firm learn new tricks? A material account of entrepreneurial opportunity. Bus Hist, 55, 53-72.

Schroeder, J., Borgerson, J., \& Wu, Z. (2015). A brand culture approach to Chinese cultural heritage brands. J of Brand Manag, 22(3), 261-279.

Sekaran, U. (1983). Methodological and theoretical issues and advancements in cross-cultural research. J of Internat Bus Studies, 14, 61-73.

Siggelkow, N. (2007). Persuasion with case studies. Acad Manag J, 50, 20-24.

Spielmann, N. (2014). Brand equity for origin-bounded brands. J of Brand Manag, 21, 189-201.

Spielmann, N. \& Williams, C. (2016). It goes with the territory: Communal leverage as a 
marketing resource. J Bus Res, 69, 5636-5643.

Thach, L., \& Charters, S. (2016), Best practices in global wine tourism: 15 case studies from around the world, Putnam Valley, NY: Miranda Press.

Tyler, B., Lahneman, B., Beukel, K., Cerrato, D., Minciullo, M., Spielmann, N., \& Discua Cruz, A. (2018). SME managers' perceptions of competitive pressure and the adoption of environmental practices in fragmented industries: A multi-country study in the wine industry. Organ \& Environ, forthcoming https://doi.org/10.1177/1086026618803720

Urde, M., \& Greyser, S. A. (2015). The Nobel Prize: The identity of a corporate heritage brand. $J$ of Prod \& Brand Manag, 24, 318-332.

Urde, M., \& Greyser, S. A. (2016). The corporate brand identity and reputation matrix-The case of the Nobel prize. $J$ of Brand Manag, 23, 89-117.

Urde, M., Greyser, S. A., \& Balmer, J. M. T. (2007). Corporate brands with a heritage. J of Brand Manag, 15, 4-19.

Warnaby, G., \& Medway, D. (2013). What about the "place" in place marketing? Mark Theory, $13,345-363$.

Warnaby, G., Medway, D., \& Bennison, D. (2010). Notions of materiality and linearity: The challenges of marketing the Hadrian's wall place "product." Environ and Plan A, 42, 13651382.

Winter, M., Fitzgerald, R., Heck, R., Haynes, G., \& Danes, S. (1998). Revisiting the study of family businesses: methodological challenges, dilemmas, and alternative approaches. Family Bus Rev, 11, 239-252.

Yin, R. K. (2003). Case study research: Design and methods (3rd ed.). Thousand Oaks, CA: Sage. 
Table 1: Sample Statistics

\begin{tabular}{|l|l|l|l|l|}
\hline Category & $\begin{array}{l}\text { Brand Name } \\
\text { (acronym) }\end{array}$ & Origin & $\begin{array}{l}\text { Year } \\
\text { Founded }\end{array}$ & $\begin{array}{l}\text { Average Annual } \\
\text { Production (btls) }\end{array}$ \\
\hline Old World & $\begin{array}{l}\text { Champagne Regnier } \\
\text { (Regnier) }\end{array}$ & Champagne, France & $\begin{array}{l}1763 \\
(1921)^{*}\end{array}$ & 750,000 \\
\cline { 2 - 5 } & $\begin{array}{l}\text { Cantine Cinque } \\
\text { (Cinque) }\end{array}$ & Piacenza, Italy & 1882 & $6,500,000$ \\
\cline { 2 - 5 } & $\begin{array}{l}\text { Casa Vinocola Zebra } \\
\text { (Zebra) }\end{array}$ & Vincenza, Italy & 1821 & $40,000,000$ \\
\hline New World & $\begin{array}{l}\text { Siciliano } \\
\text { (Siciliano) }\end{array}$ & Niagara, Canada & 1993 & $1,200,000$ \\
\cline { 2 - 5 } & $\begin{array}{l}\text { River Winery } \\
\text { (River) }\end{array}$ & \begin{tabular}{l} 
Cornwall, England, \\
\cline { 2 - 5 }
\end{tabular} & $\begin{array}{l}\text { Roberts Vineyards } \\
\text { (Roberts) }\end{array}$ & North Carolina, USA \\
\cline { 2 - 5 } & $\begin{array}{l}\text { Aksel Winery } \\
\text { (Aksel) }\end{array}$ & Funen, Denmark & 2009 & 70,000 \\
\hline
\end{tabular}

* Winegrowers since 1763, wine producers since 1921 
Figure 1: A model of corporate heritage identity across cultural contexts

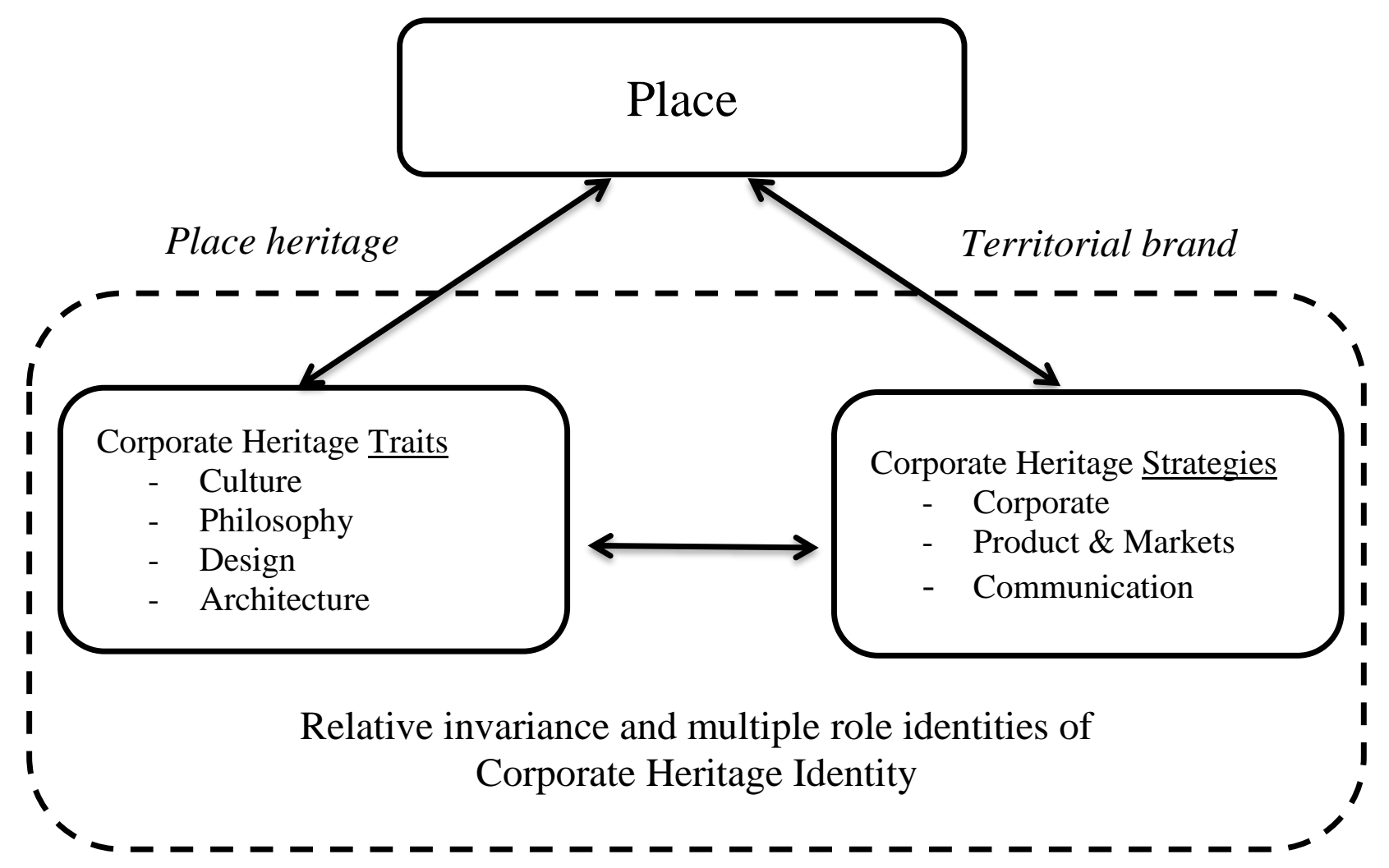

